\title{
Hydrogen Peroxide Production in Leukocytes during Cerebral Hypoxia and Reoxygenation with $100 \%$ or $21 \%$ Oxygen in Newborn Piglets
}

\author{
STEFAN KUTZSCHE, PILVI ILVES, OLE JORGEN KIRKEBY, AND OLA DIDRIK SAUGSTAD \\ Department of Pediatric Research [S.K., O.D.S.], Institute for Surgical Research [S.K.], the National \\ Hospital, Oslo, Norway; Department of Neurosurgery, Ullevål Hospital, Oslo, Norway [S.K., O.J.K.]; and \\ Department of Pediatrics, Tartu University Hospital, Estonia [P.I.]
}

\begin{abstract}
The aim of this study was to investigate whether reoxygenation with $21 \% \mathrm{O}_{2}$ rather than $100 \% \mathrm{O}_{2}$ results in reduced hydrogen peroxide $\left(\mathrm{H}_{2} \mathrm{O}_{2}\right)$ concentrations in neutrophils (PMN). Piglets (2-4 d old) exposed to severe hypoxia (inspired fraction of oxygen, 0.08) were randomized to resuscitation with $21(n=$ 13 ) or $100 \% \mathrm{O}_{2}(n=12)$. Five animals served as controls. $\mathrm{H}_{2} \mathrm{O}_{2}$ concentrations in PMN in terms of rhodamine 123 (Rho 123) fluorescence intensity from arterial and superior sagittal sinus blood were quantified by flow cytometry. Laser Doppler flowmetry (LDF) was used to assess cortical blood perfusion. During hypoxia, Rho 123 increased in arterial PMN in both study groups by 15 and $32 \%$, respectively $(p<0.05)$. In cerebral venous $\mathrm{PMN}$, the increase was less dominant $(p=0.06)$. Reoxygenation with 100 or $21 \% \mathrm{O}_{2}$ had no different effect on Rho 123 in arterial $\mathrm{PMN}$. In cerebral venous PMN, Rho 123 was approximately $40 \%$ higher after $60 \mathrm{~min}$ and $30 \%$ higher after $120 \mathrm{~min}$ compared with corresponding data in the $21 \% \mathrm{O}_{2}$ group $(p<0.05$ ), which were close to baseline levels. Further, $\mathrm{O}_{2}$ treatment in both groups induced PMN accumulation in arterial blood $(p<0.05)$. Laser Doppler flowmetry signals increased during transient hypoxia ( $p<0.0001$ compared with baseline) and were normalized after reoxygenation in both study groups. In conclusion, arterial
\end{abstract}

\section{ABSTRACT}

and cerebral venous $\mathrm{H}_{2} \mathrm{O}_{2}$ concentration in PMN tended to increase during hypoxia. During reoxygenation, $\mathrm{H}_{2} \mathrm{O}_{2}$ concentration in PMN in the cerebral circulation was low with $21 \% \mathrm{O}_{2}$ but remained high with $100 \% \mathrm{O}_{2}$ ventilation. We speculate that oxygen should be reintroduced with more caution during neonatal resuscitation. (Pediatr Res 49: 834-842, 2001)

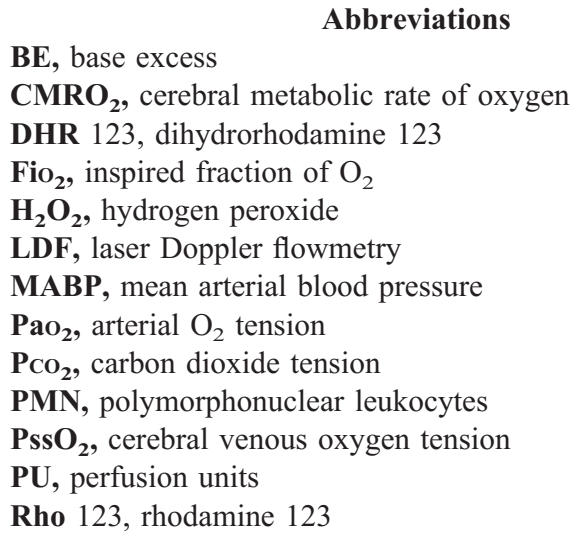

The primary release of products of the sequential reduction of oxygen, superoxide radical $\left(\mathrm{O}_{2}^{-}\right)$and $\mathrm{H}_{2} \mathrm{O}_{2}$, and the secondary production of hydroxyl radical $\left(\mathrm{HO}^{-}\right)$constitute the molecular mechanism of oxygen toxicity. Any system producing $\mathrm{O}_{2}{ }^{-}$ will, as a result of the dismutase reaction, also produce $\mathrm{H}_{2} \mathrm{O}_{2}$. Although stable, the damaging redox properties of $\mathrm{H}_{2} \mathrm{O}_{2}$ and its ability to form highly reactive free radicals in the presence of transition metal ions have caused the body to form defenses against it. The role of oxygen toxicity in the development of perinatal hypoxic-ischemic encephalopathy is still a matter of

Received November 16, 1999; accepted July 11, 2000.

Correspondence and reprint requests: Stefan Kutzsche, M.D., Department of Pediatrics, Ullevaal University Hospital, N-0407 Oslo, Norway; e-mail: stefan.kutzsche@klinmed.uio.no

Supported by grants from the Faculty of Medicine, University of Oslo, the AGA AB Medical Research Fund, and Rolf Geir Gjertsen Foundation. debate. The principal hypothesis put forward to explain this process is the oxygen free radical theory $(1,2)$.

Stimulation of PMN during hypoxia-reoxygenation may increase the concentration of reactive oxygen species (3) in these cells. To date, the production of $\mathrm{H}_{2} \mathrm{O}_{2}$ in PMN during hypoxia and resuscitation with pure or air-mixed $\mathrm{O}_{2}$ has not been studied in detail. Reoxygenation is necessary to prevent further injury to neuronal tissue, but the renewed availability of $\mathrm{O}_{2}$ to previously hypoxic brain tissue may also have detrimental effects both with respect to the microcirculation and to the parenchyma of the brain. The production of reactive oxygen metabolites may be proportional to $\mathrm{PaO}_{2}$, and the oxygen tension achieved during reactive hyperemia and reoxygenation with $\mathrm{O}_{2}$ concentrations higher than $21 \%$ may generate a correspondingly higher burst of these metabolites. However, we 
do not know with certainty whether the production of reactive oxygen species during resuscitation depends on the concentration of inspired $\mathrm{O}_{2}(4-7)$.

The aim of the present study was to investigate the hypothesis that arterial and cerebral venous PMN activated by hypoxia produce higher $\mathrm{H}_{2} \mathrm{O}_{2}$ concentrations by reoxygenation with $100 \%$ compared with $21 \% \mathrm{O}_{2}$. For this purpose, newborn piglets primarily exposed to hypoxia were randomized to resuscitation with 100 or $21 \% \mathrm{O}_{2}$. The conversion of DHR 123 into Rho 123 was used as a fluorescent marker of $\mathrm{H}_{2} \mathrm{O}_{2}$ production in white blood cell suspensions. We studied the applicability of the oxidative dye DHR 123 as an available sensitive direct indicator of $\mathrm{H}_{2} \mathrm{O}_{2}$ content in PMN. Further, we characterized the temporal course of the cortical microvascular blood perfusion in the cortex and the $\mathrm{CMRO}_{2}$ during hypoxia and reoxygenation. Regional cerebral microcirculation was simultaneously monitored using the LDF technique.

\section{METHODS}

Animal preparation. The experiments were performed on 2-4-d-old newborn piglets of both sexes, weighing from 1125 to $2065 \mathrm{~g}(1577 \pm 50 \mathrm{~g})$. Anesthesia was induced by mask inhalation of 3\% halothane (Fluothane, Zeneca, Oslo, Norway) mixed with $\mathrm{O}_{2}$ until unconsciousness was achieved. Halothane inhalation was discontinued when a 3.5-uncuffed endotracheal tube (SIMS Portex, Hythe, UK) was inserted via tracheotomy and connected to a volume-controlled ventilator $(900 \mathrm{~B}$, Siemens Elema, Solna, Sweden). A humidifier (Humid-Vent Micro +3.5, Louis Gibeck, Upplands Väsby, Sweden) was connected to the endotracheal tube. Tidal volume was kept at 30 $\mathrm{mL} / \mathrm{kg}$ and the respiratory frequency at 40 breaths $/ \mathrm{min}$ to achieve a $\mathrm{PaCO}_{2}$ at a range of 4-6 kPa. End-tidal $\mathrm{CO}_{2}$ was continuously measured with a $\mathrm{CO}_{2}$ monitor (Engström Eliza Plus, Datex-Ohmeda AB, Bromma, Sweden). $\mathrm{Fio}_{2}$ was set at 0.21 . Inspired $\mathrm{O}_{2}$ concentration was monitored with an oximeter (Datex Instrumentation Corp., Helsinki, Finland), which was calibrated before the start of each experiment.

After cannulation of the intermediate or lateral auricular vein, bolus injections of $6-10 \mathrm{mg} / \mathrm{kg}$ of sodium pentobarbital, $20 \mu \mathrm{g} / \mathrm{kg}$ of fentanyl (Leptanal, Janssen-Cilag, Holmlia, Norway), and $0.1 \mathrm{mg} / \mathrm{kg}$ of pancuronium bromide (Pavulon, Organon Teknika, Cambridge, UK) were given. A continuous sodium pentobarbital infusion $\left(6 \mathrm{mg} \cdot \mathrm{kg}^{-1} \cdot \mathrm{h}^{-1}\right)$ was administered throughout the experiments except during the hypoxic period. Repeated doses of $2-4 \mu \mathrm{g} / \mathrm{kg}$ of fentanyl and 0.05 $\mathrm{mg} / \mathrm{kg}$ of pancuronium bromide were given hourly. An i.v. infusion containing $0.75 \% \mathrm{NaCl}$ and $1.25 \%$ glucose was given at a rate of $10 \mathrm{~mL} \cdot \mathrm{kg}^{-1} \cdot \mathrm{h}^{-1}$. Polyethylene catheters (Portex PE 5, inside diameter $0.58 \mathrm{~mm}$, SIMS Portex Ltd., Hythe, UK) were inserted into the left external jugular vein for maintenance of anesthesia and fluid replacement and into the right femoral artery for blood pressure monitoring. Body temperature was monitored by a rectal thermometer and kept at $36.5-38.5^{\circ} \mathrm{C}$ by a radiant heating lamp and warm blankets, minimizing temperature-induced variations on metabolism.

The animals were then laid in a prone position. After infiltration of $2-3 \mathrm{~mL}$ of $1.0 \%$ lidocaine (Astra Zeneca,
Södertälje, Sweden), a longitudinal midline incision extending from the glabella to the $\mathrm{C} 2$ vertebra was made. A stereotaxic head holder (David Kopf Instruments, Tujunga, CA, U.S.A.) was used to clamp the head by ear bars and a mouthpiece bar at three points. Bone landmarks were used to define the planes. The axial horizontal plane was defined by a line passing through the bregma and lambda at right angles to the vertical planes. All coordinates were defined by the position of the bregma. Four holes, $3 \mathrm{~mm}$ in diameter, were drilled in the frontoparietal area of the skull. An 18-gauge cannula was inserted into the superior sagittal sinus for blood sampling. Two laser Doppler microprobes were placed in the exposed cortex with the dura removed by small incisions. The laser Doppler probes were initially held in position with methylmethacrylate (Histoacryl, Braun Melsungen AG, Melsungen, Germany) $16 \mathrm{~mm}$ anterior and $4.5 \mathrm{~mm}$ bilateral to the midline. To achieve permanent stability, the probes were inserted through cork cylinders, which fitted the hole in the skull. The fiber-tip position was set at $3 \mathrm{~mm}$ below the cortical surface in the frontal lobes at $0^{\circ}$ from the vertical. The laser Doppler probes were connected to master probes with screw couplings (model PF 318, Perimed AB, Stockholm, Sweden). A nitric oxide-sensitive electrode was inserted in the left cortex. The arterial cannula was connected to a pressure transducer (Baxter Uniflow 43-212, Bentley Laboratories, Europe B.V., Uden, Netherlands) for continuous recording of arterial blood pressure and for collecting blood samples for the DHR 123 assay for analysis of blood gases and $\mathrm{pH}$ measurements. LDF measurements and arterial blood pressure recordings were transferred to a computer program by use of an analogue-to-digital converter (model M100 WS, Biopac Systems Inc., Santa Barbara, CA, U.S.A.) at a sample rate of $2 / \mathrm{s}$.

Blood samples. To measure blood gases and acid base status, $0.5 \mathrm{~mL}$ of arterial and sagittal sinus blood was taken before hypoxemia, 2, 5, and $30 \mathrm{~min}$ after start, at the end of hypoxemia, and at 5, 30,60, and 120 min of reoxygenation. The withdrawn blood was replaced by 2.5 -fold amounts of normal saline. Temperature-corrected arterial blood gases were analyzed with an AVL 945 automatic blood gas system (AVL Biomedical Instruments, Schaffhausen, Switzerland). Blood glucose was regularly analyzed using the hexokinase method in plasma (Gluco-quant Glucose, Boehringer Mannheim GmbH, Mannheim, Germany). Ten to $15 \mathrm{~mL}$ of glucose $5 \%$ solution was given i.v. when serum glucose concentration was $<4$ $\mathrm{mmol} / \mathrm{L}$. C-reactive protein was checked routinely to detect responses due to neutrophil activation for reasons other than changes in ventilatory $\mathrm{O}_{2}$ concentrations (e.g. infection) and was measured in EDTA plasma by an immunologic test (Tinaquant CRP, Boehringer Mannheim GmbH, Germany) at the same time points as for the $\mathrm{H}_{2} \mathrm{O}_{2}$ analysis. Leukocyte differential count was performed on a hematology cell counter (Cell Dyn 3500, Abbott Laboratories, Abbott Park, IL, U.S.A.) using arterial blood samples.

Reagents. FACS lysing solution $(10 \times$ concentrate $)$ was obtained from Becton Dickinson Immunocytometry Systems (Becton Dickinson, Lincoln Park, NJ, U.S.A.). DHR 123, MW 346.38, molecular formula $\mathrm{C}_{21} \mathrm{H}_{18} \mathrm{~N}_{2} \mathrm{O}_{3}$ (Molecular Pobes, Eugene, OR, U.S.A.), sensitive to both light and air, was 
dissolved in dimethylsulfoxide (Sigma Chemical Co., St. Louis, MO, U.S.A.) at a concentration of $500 \mu \mathrm{M}$, and aliquots were stored in deoxygenated containers at $-20^{\circ} \mathrm{C}$ in the dark.

Cell isolation. Five hundred microliters of blood (Microtainer Brand, EDTA anticoagulated, Becton Dickinson, Vacutainer Systems, Franklin Lakes, NJ, U.S.A.) was drawn simultaneously from the femoral artery and from the superior sagittal sinus. For immediate isolation of the white blood cells (mainly neutrophils, monocytes, and lymphocytes), a mixture of 300 $\mu \mathrm{L}$ of blood and $3 \mathrm{~mL}$ of FACS lysing solution 1:10 was incubated in round-bottom polystyrene test tubes (Falcon 2058, Becton Dickinson Labware, Lincoln Park, NJ, U.S.A.). After lysis of red cells for $10 \mathrm{~min}$, leukocytes were centrifuged at 160 $\times g$ for $5 \mathrm{~min}$, the pellet was resuspended in $3 \mathrm{~mL}$ of the lysing solution, and the cells were centrifuged again at $300 \times g$ and $1200 \mathrm{rpm}$ for $5 \mathrm{~min}$. Finally, they were washed once in $3 \mathrm{~mL}$ of Dulbecco's PBS $+2 \%$ FCS and centrifuged at $200 \times g$ and $1000 \mathrm{rpm}$ for $5 \mathrm{~min}$. The pellet was then incubated in $400 \mu \mathrm{L}$ of PBS $+2 \%$ FCS +5 mmol glucose, and the cells were kept at $4^{\circ} \mathrm{C}$ until subjected to flow cytometric analysis within $2 \mathrm{~h}$.

Measurement of $\mathrm{H}_{2} \mathrm{O}_{2}$ concentration in neutrophils. The pharmacologic probe DHR 123 was applied as a green fluorescence indicator in the flow cytometric analysis of $\mathrm{H}_{2} \mathrm{O}_{2}$ in neutrophils, as first described by Bass et al. (8). The principle behind the $\mathrm{H}_{2} \mathrm{O}_{2}$ assay is oxidation of the nonfluorescent compound DHR 123 into the highly fluorescent compound Rho 123 by primarily neutrophil-associated $\mathrm{H}_{2} \mathrm{O}_{2}(9)$. The extracellular oxidation of DHR 123 to Rho 123 is extremely slow unless catalyzed by an enzyme with peroxidase activity. Myeloperoxidase from the azurophilic granules is the only peroxidase that has been described in neutrophils (10), and it has been shown to be essential for intracellular oxidation of DHR coupled with $\mathrm{H}_{2} \mathrm{O}_{2}$ activity $(11,12)$. Rho 123 cannot pass the plasma membrane and is retained within the cell. Neutrophil Rho 123 fluorescence intensity is proportional to the concentration of generated $\mathrm{H}_{2} \mathrm{O}_{2}$ and was detected by a $488-\mathrm{nm}$ argon laser-equipped flow cytometer. The reaction is highly specific for respiratory burst activity, as it occurs in neutrophil subpopulations (13). Spontaneous oxidation of DHR 123 to Rho 123 over time was counteracted by keeping the dye solution refrigerated during the experiment and prewarmed to $37^{\circ} \mathrm{C}$ in the dark 30 min before use. DHR 123 was added at a final concentration of $30 \mu \mathrm{M}$, and the samples were incubated at room temperature for $5 \mathrm{~min}$ in the dark. After centrifugation at $500 \times g$ for $5 \mathrm{~min}$, they were resuspended in $400 \mu \mathrm{L}$ of PBS $+2 \% \mathrm{FCS}+5 \mathrm{mmol}$ glucose. Dye uptake in granulocyte cells is fast and is considered to be temperature-insensitive, and a steady state was quickly achieved.

Flow cytometry analysis. A standard flow cytometer (FACScan, Becton Dickinson, Immunocytometry Systems, San Jose, CA, U.S.A.) with excitation at $488 \mathrm{~nm}$ was used. Monocytes, lymphocytes, and dead cells were distinguished from intact granulocytes by measurement of the cellular forward angle and $90^{\circ}$ side scatter. Fifteen $\times 10^{3}$ events were acquired for data storage. For identifying neutrophils, an appropriate freeform polygonal software gate was carefully set around the granulocyte population, created as a two-parameter cytogram dot plot (Fig. 1). Each sample was run in this setup mode until

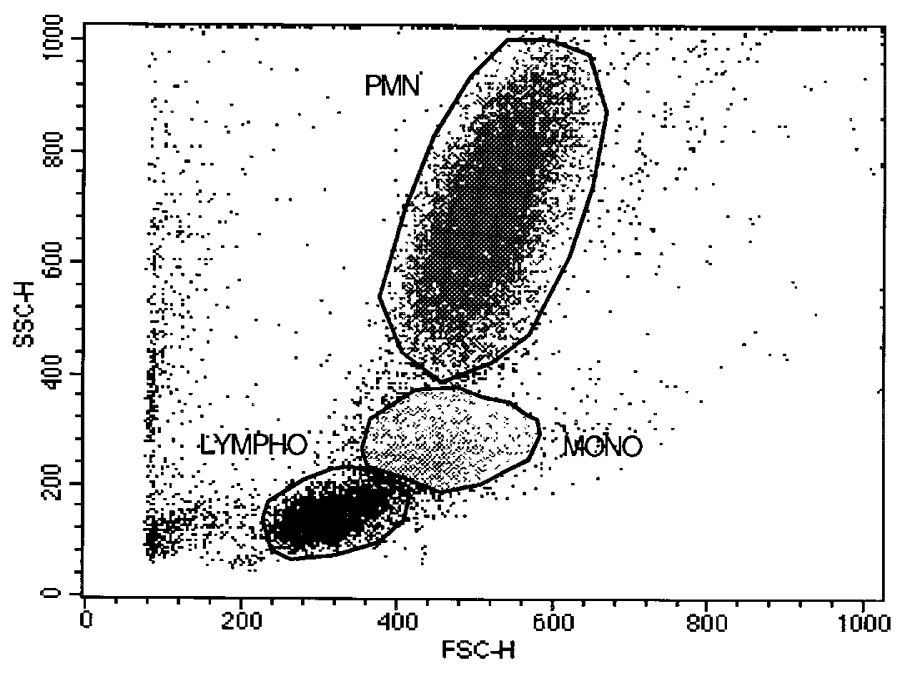

Figure 1. Two-parameter cytogram dot plot from a baseline sample. $P M N$, neutrophil leukocytes $62.8 \%$; MONO, monocytes $4.3 \%$; LYMPHO, lymphocytes $21.3 \%$; SSC-H, side scatter; $F S C$ - $H$, forward scatter.

the granulocyte acquisition gate was established. Gated cells were analyzed for their fluorescence properties. Rho 123 green fluorescence was collected in the FL-1 channel $(530 \mathrm{~nm}$, standard FITC filter set), and a fluorescence histogram was plotted (Fig. 2). The linear channels of the analog digital converter were reconverted to log values for this purpose $\left(1-10^{4}\right)$. Data that met the gating criterion were collected in list mode and processed for statistical analysis. Because the flow cytometer acquisition gives relative semiquantitative and not absolute values of the Rho 123 fluorescence intensities, $\mathrm{H}_{2} \mathrm{O}_{2}$ concentration is measured in terms of $\Delta \ln$ of baseline values and not in pmol concentrations in the detected cell clusters. DHR 123-free samples were run to test interfering background substances and were all found to be negative. Generation of $\mathrm{H}_{2} \mathrm{O}_{2}$ was measured in cell suspensions derived from the blood samples during the experiments. The values obtained are directly proportional to the average $\mathrm{H}_{2} \mathrm{O}_{2}$ generation within the reacting cells. The CELLQuest FACStation software (Becton Dickinson, Immunocytometry Systems, San Jose, CA, U.S.A.) for acquisition and analysis was run on a Macintosh computer.

Measurement of cortical microvascular blood perfusion. LDF has been established as a reliable method for the measurement of regional microvascular blood perfusion (14). The two-channel laser Doppler flowmeter (Periflux 4001 Master, Perimed AB, Stockholm, Sweden) emits a low-power 2-mW helium-neon laser light with a wavelength of $632.8 \mathrm{~nm}$, which is directed to the tissue by the optical fibers (PF 319:0, $210 \mathrm{~mm}$ long and $0.5 \mathrm{~mm}$ in diameter). The magnitude and frequency of the Doppler shifted light are proportional to the number and velocity of blood cells moving through the illuminated area of the tissue. Photodetectors sample frequency information and convert back-scattered light into electrical signals that are measured in millivolts. Flowmeters provide relative, not absolute, values of blood flow, so that the measurement of mainly red blood cell flux by LDF is expressed in arbitrary PU. Directional blood flow is not measured. A good correlation between LDF and radionuclide-labeled microspheres for measuring cerebral blood flow in rabbits (coefficient of 0.92) (14) 

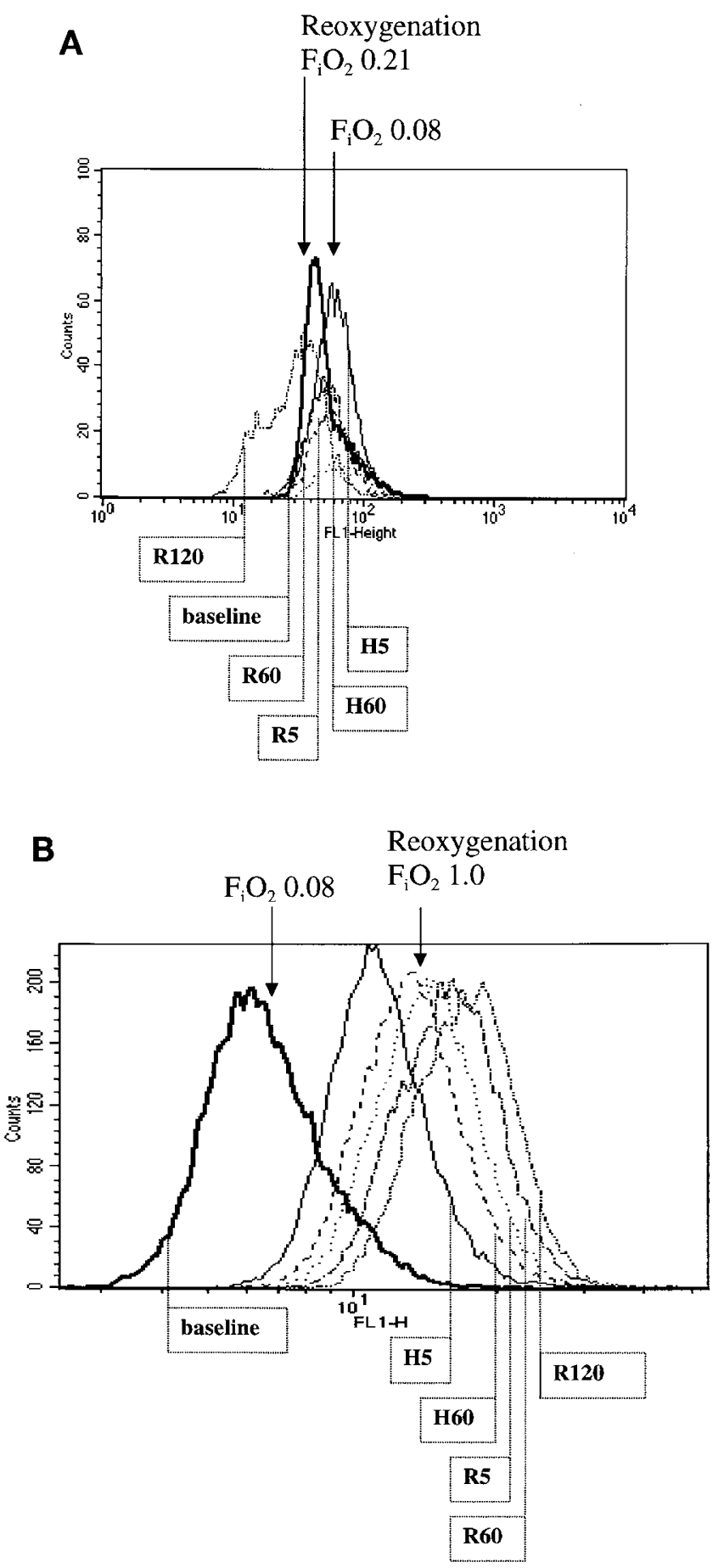

Figure 2. Rho 123 fluorescence histograms. Relative changes in $\mathrm{H}_{2} \mathrm{O}_{2}$ concentration are proportional to the Rho 123 fluorescence intensity. Values at baseline, during hypoxia $\left(\mathrm{FiO}_{2}=0.08\right)$ at $5(\mathrm{H} 5)$ and $60(\mathrm{H} 60) \mathrm{min}$, during reoxygenation with $21 \% \mathrm{O}_{2}$ at $5(R 5), 60(R 60)$, and $120(R 120) \mathrm{min}$ are shown. Each measurement is presented as one graph (overlay). Movement of the curves on the $x$ axis (logarithmic scale) to the right is associated with an increase in Rho 123 fluorescence intensity, movement to the left with a decrease. FL-1, indicates FL-1 channel. $(A) \mathrm{H}_{2} \mathrm{O}_{2}$ concentration during hypoxia and during reoxygenation with $21 \% \mathrm{O}_{2}$ in one animal. $(B) \mathrm{H}_{2} \mathrm{O}_{2}$ concentration during hypoxia and during reoxygenation with $100 \% \mathrm{O}_{2}$ in one animal.

and in pigs (15) has been reported. The reference illuminated area for this type of probe is approximately $1.0-3.5 \mathrm{~mm}^{3}$ of tissue (16). The signals were considered inadequate if the LDF was nonpulsatile or the measurements were less than $20 \mathrm{PU}$ at baseline. Postmortem values were considered to be zero blood flow and subtracted from actual values. Left- and right-side LDF measurements were monitored by two independent channels.

Experimental protocol. The animals were allowed to stabilize after completion of instrumentation for $1 \mathrm{~h}$ before the start of the experiment. After baseline recordings, hypoxia was produced by the inhalation of $8 \% \mathrm{O}_{2}$ in $92 \%$ nitrogen. Hypoxia was terminated when MABP was $<15 \mathrm{~mm} \mathrm{Hg}$ or $\mathrm{BE}<-20$ $\mathrm{mmol} / \mathrm{L}$ or $\mathrm{pH}<7.0$. Animals were randomized at the end of hypoxemia for reoxygenation with either $21 \% \mathrm{O}_{2}(n=13)$ or $100 \% \mathrm{O}_{2}(n=12)$ for $30 \mathrm{~min}$, followed by $21 \% \mathrm{O}_{2}$ for another $1.5 \mathrm{~h}$. Control animals were exposed to $21 \% \mathrm{O}_{2}$ throughout the observation time of $4 \mathrm{~h}(n=5)$. Two laser Doppler flow signals, MABP, and nitric oxide (NO) electrode signals (data not shown) were continuously recorded throughout the experiment.

Calculated variables and statistical analysis. $\mathrm{CMRO}_{2}$ was calculated by the following formula: $\left(\mathrm{CaO}_{2}-\mathrm{CssO}_{2}\right) \times \mathrm{LDF}$, where $\mathrm{CaO}_{2}$ is the arterial oxygen content $=(\mathrm{Hb}) \times($ carrying capacity $\mathrm{Hb}) \times\left(\mathrm{SaO}_{2} \%\right)+\left(\mathrm{PaO}_{2}\right) \times($ solubility of oxygen in blood), and $\mathrm{CssO}_{2}$ is the cerebral venous oxygen content $=$ $(\mathrm{Hb}) \times($ carrying capacity $\mathrm{Hb}) \times\left(\mathrm{SssO}_{2} \%\right)+\left(\mathrm{PssO}_{2}\right) \times$ (solubility of oxygen in blood). $\mathrm{CMRO}_{2}$ values were displayed as relative numbers.

Variables recorded during a 15 -s period were averaged to obtain one measuring point. Laser Doppler signals from two channels were averaged for each measuring point to use in statistical analysis. Because the laser Doppler provides relative values expressed in arbitrary PU rather than in blood flow in $\mathrm{mL} / 100 \mathrm{~g}$ tissue/min, data of cortical microvascular blood perfusion were expressed as percentages in relation to baseline.

Changes from baseline DHR fluorescence intensity were expressed as percentages of baseline.

All values are presented as mean \pm SEM. A mixed-model ANOVA for repeated measurements was used to investigate the effect of time, group, and group-by-time interactions. The effect of time within each group was studied by a 1-way analysis for repeated measurements. When a group-by-time effect was found, the $t$ test was used to compare the baseline or the end-of-hypoxia values and the peak values at 5, 60, and 120 min of reoxygenation. This model was used to compare the treatment groups with regard to the following variables: MABP, $\mathrm{pH}, \mathrm{BE}, \mathrm{PCO}_{2}, \mathrm{PO}_{2}, \mathrm{C}$-reactive protein, arterial oxygen saturation $\left(\mathrm{SO}_{2}\right)$, DHR fluorescence, leukocytes, PMN, and $\mathrm{CMRO}_{2}$. A $p$ value $<0.05$ was considered statistically significant. Calculations were performed employing Stat View version 3.1 for Macintosh, Abacus Concepts, Inc., Berkley, CA, U.S.A.

Approval. The present study was performed with the consent of the Institutional Animal Care and Use Committee of the University of Oslo. The experiments conformed to the guidelines for the care and handling of laboratory animals published by the European Convention for the Protection of Vertebrate Animals Used for Experimental and Other Scientific Purposes of March 18, 1986. 


\section{RESULTS}

The total duration of hypoxia was $66 \pm 2 \mathrm{~min}$ in the $100 \%$ $\mathrm{O}_{2}$ group and $71 \pm 3 \mathrm{~min}$ in the $21 \% \mathrm{O}_{2}$ group (NS). There were no significant differences between any of the three groups in any measured variable at baseline or between the two reoxygenated groups at the end of the hypoxemic period.

Physiologic variables. Data for MABP are shown in Table 1. The acute responses (after $90 \mathrm{~s}$ ) to hypoxemia led to a rapid but not significant increase in MABP of $4 \mathrm{~mm} \mathrm{Hg}$ (both groups combined), which then decreased significantly toward the end of the hypoxemic period. During the first 5 min of reoxygenation, MABP increased by $44 \%$ in the $100 \% \mathrm{O}_{2}$ group and by $18 \%$ in the $21 \% \mathrm{O}_{2}$ group (compared with end of hypoxia). However, the group-by-group differences were not significant. At the end of the reoxygenation period, the MABP was $49 \pm$ $5 \mathrm{~mm} \mathrm{Hg}$ in the room air group and $55 \pm 5 \mathrm{~mm} \mathrm{Hg}$ in the $100 \%$ $\mathrm{O}_{2}$ group, which was significantly lower than baseline values $(p<0.05)$. Group-by-group effects during reoxygenation were not significant $(p=0.2)$.

CMRO2. Calculations of $\mathrm{CMRO}_{2}$ during hypoxia and reoxygenation with 100 or $21 \% \mathrm{O}_{2}$ are shown in Table 2 . During hypoxia, $\mathrm{CMRO}_{2}$ decreased by 35 to $50 \%$ ( $p<0.005$ versus baseline) in the two hypoxemic groups. Reoxygenation with 100 and $21 \% \mathrm{O}_{2}$ produced different responses at $60 \mathrm{~min}$ of reoxygenation. In the $100 \%$ group, $\mathrm{CMRO}_{2}$ rose from $2.8 \pm$ 0.5 at the end of hypoxia to $4.5 \pm 0.6(p<0.05)$. $\mathrm{CMRO}_{2}$ was higher in the $21 \% \mathrm{O}_{2}$ group and rose from $3.7 \pm 0.5$ to $5.8 \pm$ 0.5 at the end of hypoxemia (NS compared with the end of hypoxia). At $60 \mathrm{~min}$ of reoxygenation, the group-by-group comparison displayed a higher $\mathrm{CMRO}_{2}$ in the room air group than in the $100 \% \mathrm{O}_{2}$ group $(p<0.05)$. However, at $120 \mathrm{~min}$ of reoxygenation, $\mathrm{CMRO}_{2}$ in all groups was restored, and no differences between the groups were found.

Blood gases. $\mathrm{pH}, \mathrm{PCO}_{2}, \mathrm{PO}_{2}, \mathrm{BE}$, and $\mathrm{SO}_{2}$ values from arterial and venous sagittal sinus blood are shown in Tables 3 and 4. During hypoxemia, arterial $\mathrm{pH}$ and $\mathrm{BE}$ fell as expected dramatically in both study groups. During reoxygenation, $\mathrm{pH}$ and $\mathrm{BE}$ began to revert to normal and, after $120 \mathrm{~min}$ of reoxygenation, $\mathrm{pH}$ and $\mathrm{BE}$ values were almost restored in both groups. At the end of the hypoxia period, $\mathrm{PaO}_{2}$ fell to values lower than $3.5 \mathrm{kPa}$ in both groups. During ventilation with $100 \% \mathrm{O}_{2}, \mathrm{PaO}_{2}$ rose to $50.0 \pm 5.0 \mathrm{kPa}$ in the $100 \% \mathrm{O}_{2}$ group and to $11.1 \pm 0.4 \mathrm{kPa}$ in the $21 \% \mathrm{O}_{2}$ group. At the end of the experiments, $\mathrm{O}_{2}$ tension was normalized in both groups. During hypoxia, the changes in cerebral venous $\mathrm{pH}$ and $\mathrm{BE}$ were parallel to the values obtained from arterial blood. $\mathrm{PssO}_{2}$ fell 1-2 $\mathrm{kPa}$ during hypoxia, and cerebral venous $\mathrm{O}_{2}$ saturation $\left(\mathrm{SssO}_{2}\right)$ decreased in mean $35 \%$ in the $100 \% \mathrm{O}_{2}$ group and
$24 \%$ in the $21 \% \mathrm{O}_{2}$ group ( $p<0.001$ versus baseline values). During reoxygenation with $100 \% \mathrm{O}_{2}, \mathrm{PssO}_{2}$ was $9.9 \pm 1.9 \mathrm{kPa}$ $\left(100 \% \mathrm{O}_{2}\right)$ and $5.7 \pm 0.7 \mathrm{kPa}\left(21 \% \mathrm{O}_{2}\right) . \mathrm{SssO}_{2}$ rose by approximately $40 \%$ in the $100 \% \mathrm{O}_{2}$ group and by $30 \%$ in the $21 \% \mathrm{O}_{2}$ group compared with the end-of-hypoxia values. During reoxygenation, the values declined slowly until they reached subnormal values at the end of the experiment.

$\mathrm{PaCO}_{2}$ was not significantly different between the two study groups at any time and was kept stable within the physiologic range (4.6-5.4 $\mathrm{kPa})$ throughout the experiments in all animals.

C-reactive protein, oxyhemoglobin, and plasma glucose. C-reactive protein from plasma derived from arterial and cerebral venous blood was negative $(<10 \mathrm{mg} / \mathrm{L})$ at baseline, during hypoxia, and during reoxygenation in all samples. $\mathrm{Hb}$ was stable throughout the study, and no differences were found between the groups. Plasma glucose concentrations were not different between the groups; however, a slight increase during the hypoxic period in both study groups was seen (data not shown).

White blood cells, granulocytes. The total number of circulating leukocytes in arterial blood (Fig. 3) rose from baseline by $11 \%$ at the end of the hypoxemic period in both groups (NS). This increase continued during reoxygenation, and maximal values were obtained at $120 \mathrm{~min}$ of reoxygenation: $12.3 \pm$ 1.5 cells $\times 10^{9} / \mathrm{L}$ in the $100 \% \mathrm{O}_{2}$ group versus $10.7 \pm 1.1$ at end of hypoxia $(p<0.05)$ and $13.2 \pm 2.1$ cells $\times 10^{9} / \mathrm{L}$ in the $21 \% \mathrm{O}_{2}$ group versus $8.8 \pm 1.3$ at end of hypoxia $(p<0.05)$; however, no intergroup differences were found. The relative number of circulating PMN in the $100 \% \mathrm{O}_{2}$ group rose from $36.1 \pm 5.3 \%$ at the end of hypoxia to $42.2 \pm 4.7 \%(p<0.05)$, in contrast with PMN in the $21 \% \mathrm{O}_{2}$ group in which the number was unchanged.

Rho 123 fluorescence intensity in neutrophil cells. Changes in Rho 123 fluorescence intensity during normoxia, hypoxia, and reoxygenation with 21 or $100 \% \mathrm{O}_{2}$ are shown in Table 5 for arterial and cerebral venous samples. Arterial $\mathrm{H}_{2} \mathrm{O}_{2}$ concentration in PMN increased significantly at the end of hypoxia by $14.7 \pm 4.7 \%$ and by $32.2 \pm 14.5 \%$ in the 21 and $100 \% \mathrm{O}_{2}$ groups, respectively ( $p<0.05$ versus baseline, both groups combined), with no significant difference between the two groups. During reoxygenation, baseline concentrations were obtained after $5 \mathrm{~min}$ both in the $100 \% \mathrm{O}_{2}$ group and in the $21 \%$ $\mathrm{O}_{2}$ group and did not change from this level until the end of the experiment. The concentrations in the $21 \% \mathrm{O}_{2}$ group tended to be lower than in the $100 \%$ group, but ANOVA for repeated measurements did not show a significant group-by-time difference between the two reoxygenated groups.

Table 1. MABP during baseline, hypoxia $\left(8 \% \mathrm{O}_{2}\right)$, and reoxygenation with 100 and $21 \% \mathrm{O}_{2}$

\begin{tabular}{|c|c|c|c|c|c|c|c|c|}
\hline & & & Hypoxia & & & xygenation ( & & \\
\hline \multirow{3}{*}{$\mathrm{MABP}, \mathrm{mm} \mathrm{Hg}$} & Group & Baseline & 5 & 60 & End & 5 & 60 & G120 \\
\hline & $100 \% \mathrm{O}_{2}$ & $74.8 \pm 3.8$ & $64.4 \pm 5.5$ & $53.9 \pm 5.6$ & $48.2 \pm 5.5^{*}$ & $69.7 \pm 5.4$ & $61.7 \pm 3.5$ & $49.8 \pm 4.8^{*}$ \\
\hline & $21 \% \mathrm{O}_{2}$ & $79.1 \pm 3.1$ & $78.8 \pm 5.1$ & $74.8 \pm 4.9$ & $69.1 \pm 4.7^{*}$ & $81.3 \pm 5.9$ & $66.1 \pm 5.1$ & $55.0 \pm 4.8^{*}$ \\
\hline
\end{tabular}

Results are presented as mean \pm SEM; groups: $100 \% \mathrm{O}_{2}(n=12), 21 \% \mathrm{O}_{2}(n=13)$, control $(n=5)$.

End indicates end of hypoxia. * Indicates $\mathrm{p}<0.05 v s$ baseline. 
Table 2. Changes of $\mathrm{CMRO}_{2}$ during baseline, hypoxia $\left(8 \% \mathrm{O}_{2}\right)$, and reoxygenation with 100 and $21 \% \mathrm{O}_{2}$

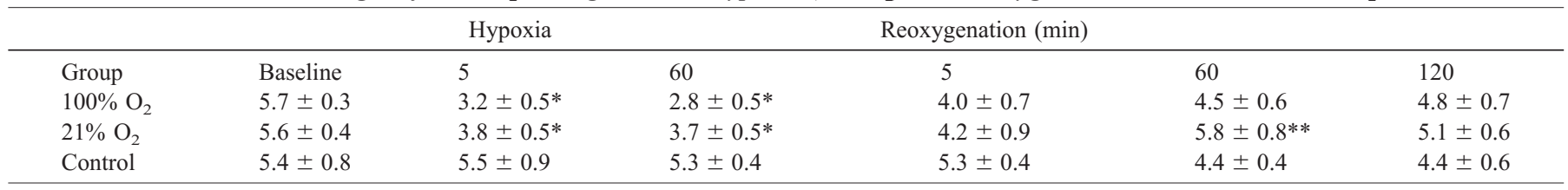

Relative changes of $\mathrm{CMRO}_{2}$. Values are calculated by the following formula: $\left(\mathrm{CaO}_{2}-\mathrm{CssO}_{2}\right) \times \mathrm{LDF}$ and presented as relative numbers. CaO $=$ arterial oxygen content; $\mathrm{CssO}_{2}=$ cerebral venous oxygen content. Results are presented as mean \pm SEM; groups: $100 \% \mathrm{O}_{2}(n=12), 21 \% \mathrm{O}_{2}(n=13)$, control $(n=5)$. * Indicates $\mathrm{p}<0.05$ compared with baseline. ${ }^{* *}$ Indicates $\mathrm{p}<0.05$ compared with $100 \% \mathrm{O}_{2}$ group.

Table 3. Arterial $\mathrm{pH}, \mathrm{PCO}_{2}, \mathrm{Po}_{2}, \mathrm{BE}$, and $\mathrm{So}_{2}$ during baseline, hypoxia (8\% $\mathrm{O}_{2}$ ), and reoxygenation with 100 and $21 \% \mathrm{O}_{2}$

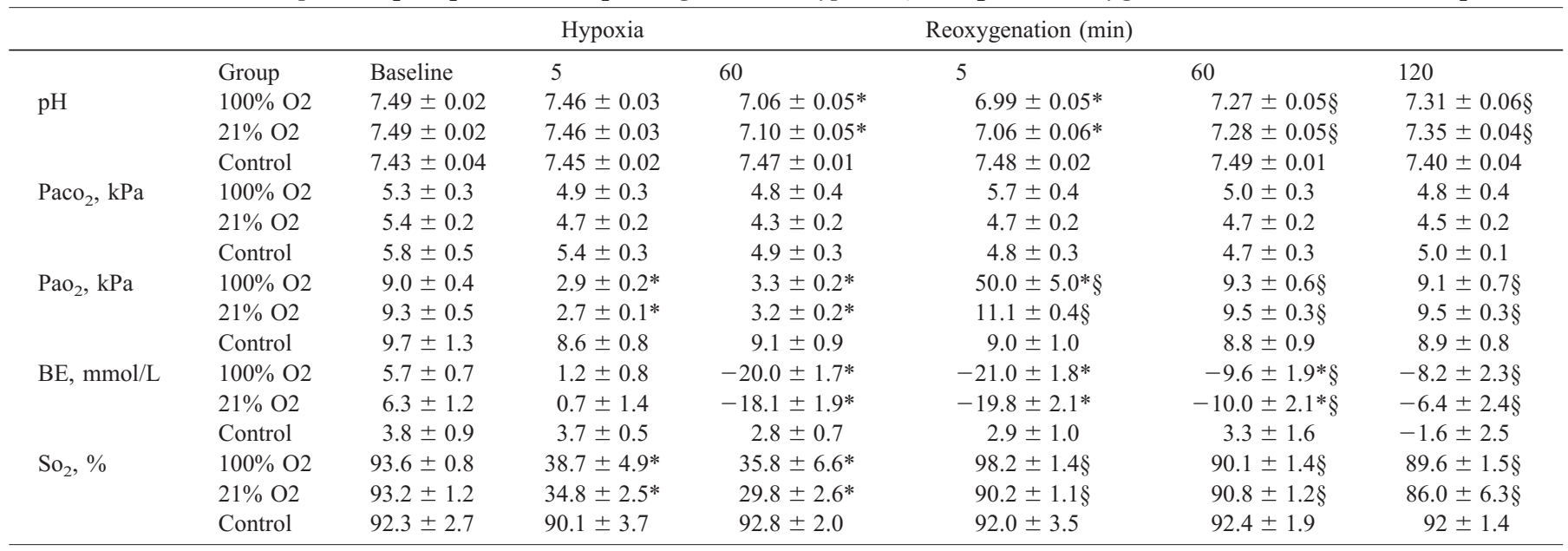

Results are presented as mean \pm SEM; groups: $100 \% \mathrm{O}_{2}(n=12), 21 \% \mathrm{O}_{2}(n=13)$, control $(n=5)$. $\mathrm{Paco}_{2}$, arterial $\mathrm{Pco}_{2}$; $\mathrm{So}_{2}$, arterial oxygen saturation. $* \mathrm{p}<0.05 v s$ control group (group difference by repeated measures ANOVA). $\S \mathrm{p}<0.05$ vs hypoxia $60 \mathrm{~min}$.

Table 4. Cerebral venous (superior sagittal sinus) $\mathrm{pH}, \mathrm{PCO}_{2}, \mathrm{Po}_{2}, \mathrm{BE}$, and $\mathrm{So}_{2}$ during baseline, hypoxia (8\% $\mathrm{O}_{2}$ ), and reoxygenation with 100 and $21 \% \mathrm{O}_{2}$

\begin{tabular}{|c|c|c|c|c|c|c|c|}
\hline & & & Hypoxia & & Reoxyge & $\mathrm{n}(\min )$ & \\
\hline \multirow{3}{*}{$\mathrm{pH}$} & Group & Baseline & 5 & 60 & 5 & 60 & 120 \\
\hline & $100 \% \mathrm{O} 2$ & $7.39 \pm 0.02$ & $7.39 \pm 0.02$ & $7.05 \pm 0.06^{*}$ & $6.96 \pm 0.05^{*}$ & $7.20 \pm 0.04 \S$ & $7.17 \pm 0.06 \S$ \\
\hline & $21 \% \mathrm{O} 2$ & $7.38 \pm 0.02$ & $7.36 \pm 0.04$ & $7.10 \pm 0.05^{*}$ & $7.06 \pm 0.05^{*}$ & $7.20 \pm 0.04 \S$ & $7.24 \pm 0.04 \S$ \\
\hline \multirow[t]{3}{*}{$\mathrm{Paco}_{2}, \mathrm{kPa}$} & $100 \% \mathrm{O} 2$ & $6.9 \pm 0.4$ & $5.6 \pm 0.2$ & $5.1 \pm 0.3$ & $6.7 \pm 0.5$ & $6.3 \pm 0.3$ & $6.9 \pm 0.5$ \\
\hline & $21 \% \mathrm{O} 2$ & $7.0 \pm 0.3$ & $5.3 \pm 0.1$ & $5.0 \pm 0.2$ & $5.5 \pm 0.2$ & $6.2 \pm 0.2$ & $6.5 \pm 0.2$ \\
\hline & Control & $6.9 \pm 0.2$ & $6.9 \pm 0.1$ & $6.6 \pm 0.2$ & $6.3 \pm 0.2$ & $6.7 \pm 0.3$ & $6.9 \pm 0.4$ \\
\hline $\mathrm{Pao}_{2}, \mathrm{kPa}$ & Control & $3.5 \pm 0.4$ & $3.0 \pm 0.3$ & $2.6 \pm 0.3$ & $3.3 \pm 0.8$ & $2.3 \pm 0.2$ & $2.3 \pm 0.2$ \\
\hline \multirow[t]{3}{*}{$\mathrm{BE}, \mathrm{mmol} / \mathrm{L}$} & $100 \% \mathrm{O} 2$ & $5.5 \pm 0.5$ & $0.0 \pm 1.0$ & $-19.6 \pm 2.1^{*}$ & $-20.9 \pm 1.7^{*}$ & $-9.4 \pm 1.9 * \S$ & $-9.3 \pm 2.7 \S$ \\
\hline & $21 \% \mathrm{O} 2$ & $4.9 \pm 1.2$ & $-2.5 \pm 2.2$ & $-17.8 \pm 1.9^{*}$ & $-18.2 \pm 2.7^{*}$ & $-9.8 \pm 2.2 * \S$ & $-6.4 \pm 2.4 \S$ \\
\hline & Control & $4.2 \pm 0.8$ & $3.7 \pm 0.6$ & $2.2 \pm 0.7$ & $2.8 \pm 0.8$ & $0.2 \pm 1.2$ & $-2.3 \pm 2.5$ \\
\hline \multirow{2}{*}{$\mathrm{So}_{2}, \%$} & $100 \% \mathrm{O} 2$ & $39.5 \pm 2.9$ & $13.6 \pm 1.5^{*}$ & $14.0 \pm 4.5^{*}$ & $68.6 \pm 7.2 \S$ & $34.2 \pm 4.6 \S$ & $21.8 \pm 2.8 \S$ \\
\hline & $21 \% \mathrm{O} 2$ & $49.4 \pm 4.2$ & $12.5 \pm 1.3^{*}$ & $12.0 \pm 5.1^{*}$ & $53.7 \pm 6.3 \S$ & $34.6 \pm 4.2 \S$ & $22.7 \pm 2.1 \S$ \\
\hline
\end{tabular}

Results are presented as mean \pm SEM; groups: $100 \% \mathrm{O}_{2}(n=12), 21 \% \mathrm{O}_{2}(n=13)$, control $(n=5) .{ }^{*} \mathrm{p}<0.05 v s$ control group (group difference by repeated measures ANOVA). $\S \mathrm{p}<0.05 v s$ hypoxia $60 \mathrm{~min}$.

At the end of hypoxia in cerebral venous blood, $\mathrm{H}_{2} \mathrm{O}_{2}$ concentration tended to increase compared with baseline $(121.1 \pm 14.1 \%$ for the $100 \%$ group and $113.7 \pm 8.6 \%$ for the $21 \%$ group, $p=0.06$; both groups combined).

During reoxygenation in the $100 \% \mathrm{O}_{2}$ group, levels of $\mathrm{H}_{2} \mathrm{O}_{2}$ remained elevated and were significantly higher both at $60 \mathrm{~min}$ ( $25.5 \%$ increase, $p<0.05$ compared with baseline) and at 120 min of reventilation ( $13.5 \%$ increase, $p<0.05$ compared with baseline), i.e. even 90 min after $\mathrm{Fio}_{2}$ had been reduced to 0.21 . In contrast, at the same time points in the $21 \% \mathrm{O}_{2}$ group, significantly lower $\mathrm{H}_{2} \mathrm{O}_{2}$ concentrations compared with the $100 \% \mathrm{O}_{2}$ group were found ( $p<0.05$ versus $100 \% \mathrm{O}_{2}$ group) and were approximately $10 \%$ lower compared with baseline.

Microvascular blood perfusion in the cortex. Regional cortical microvascular perfusion increased significantly after 5 min of hypoxia by $26 \%$ for the $100 \% \mathrm{O}_{2}$ group and by $49 \%$ for the $21 \% \mathrm{O}_{2}$ group ( $p=0.0006$ versus baseline, both groups taken together). This increase seemed to reach a steady state during the period of hypoxia, and, at the end of hypoxia, it was approximately 39 and $49 \%$ higher for the respective groups 


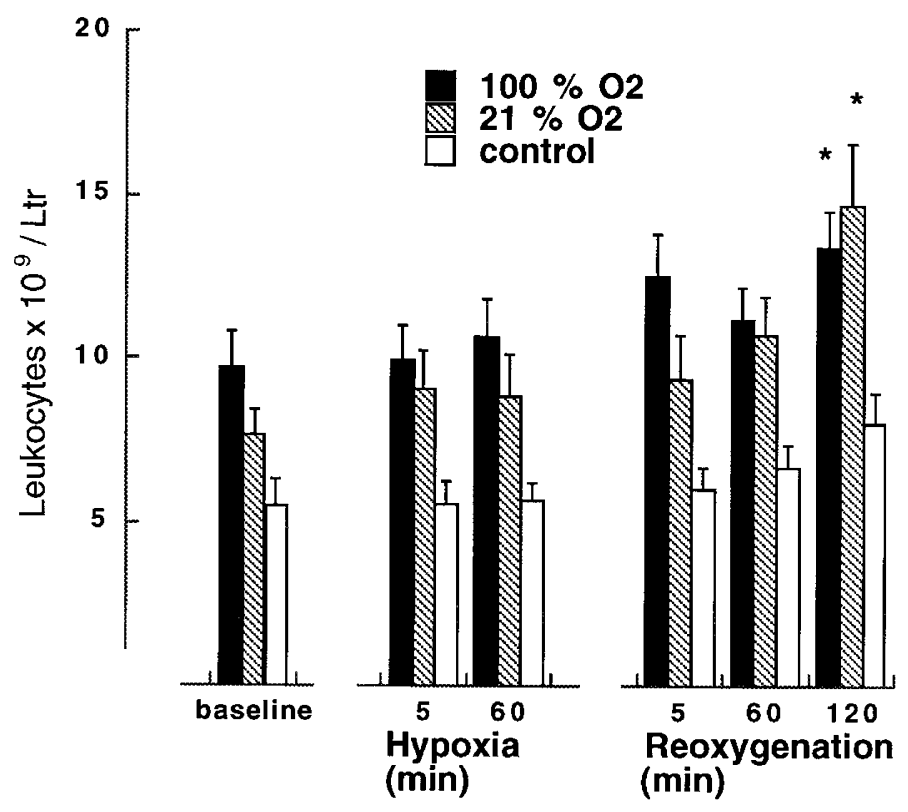

Figure 3. Leukocyte counts (cells $\times 10^{9} / \mathrm{L}$, mean \pm SEM) in arterial blood at baseline, during hypoxia, and reoxygenation with 21 or $100 \% \mathrm{O}_{2} \cdot{ }^{*} p<0.05$ vs baseline.

than their baseline values $(p<0.0001$, both groups taken together). During reoxygenation, LDF curves in both study groups returned to baseline levels and were similar to the corresponding control values of the normoxemic group. No differences were found between the two reoxygenation groups during the 2-h posthypoxic observation period (Fig. 4).

\section{DISCUSSION}

The present study showed an increased $\mathrm{H}_{2} \mathrm{O}_{2}$ concentration in PMN from arterial blood during hypoxia; by contrast, in cerebral venous blood, the $\mathrm{H}_{2} \mathrm{O}_{2}$ level in PMN tended to increase only. After reoxygenation, $\mathrm{H}_{2} \mathrm{O}_{2}$ was elevated in the $100 \% \mathrm{O}_{2}$ group and lowered in the $21 \% \mathrm{O}_{2}$ group compared with baseline. Hypoxia also resulted in an augmentation of regional cerebral blood flow in the cerebral cortex that remained until the end of hypoxemia. The cerebral microcirculation was restored as efficiently with room air as with $100 \%$ $\mathrm{O}_{2}$. After $60 \mathrm{~min}$ of reoxygenation, $\mathrm{CMRO}_{2}$ in the $21 \% \mathrm{O}_{2}$ group tended to be higher than in the $100 \% \mathrm{O}_{2}$ group.

Free radicals may stimulate the accumulation and activation of granulocytes. The exact role of PMN in triggering the oxidative-antioxidative balance during hypoxia-reoxygenation is unknown. The DHR flow cytometry assay in total leukocyte preparations used in the present study offers a direct detection system to measure intracellular $\mathrm{H}_{2} \mathrm{O}_{2}$ concentrations in PMN but not the generation of $\mathrm{O}_{2}{ }^{-}(11)$. Adherent PMN that would have escaped measurement are not included. This means that only $\mathrm{H}_{2} \mathrm{O}_{2}$ concentration in circulating PMN was monitored. Others have shown that intracellular oxidation of DHR 123 is a sensitive and reliable method of quantifying $\mathrm{H}_{2} \mathrm{O}_{2}$ in PMN $(13,17,18)$. However, flow cytometric experiments in cell suspension require cautious interpretation. Even normally stimulated PMN may respond heterogeneously, suggesting the existence of functional differences in the circulating cells (8). This heterogeneity in the oxidative response has to be taken into account.

Measurements of $\mathrm{H}_{2} \mathrm{O}_{2}$ concentrations were performed in circulating PMN in the cerebral and systemic circulation but not in the brain tissue. Neutrophils may act as inflammatory cells and are particularly important in the induction of oxidative stress in endothelial cells in the cerebral vascular bed (19, 20). Oxidative stress on endothelial cells invoked by neutrophils (and possibly monocytes, too) is at least partially responsible for the neutrophil rolling, adhesion, and finally migration through the endothelium into the tissue. Interaction of $\mathrm{H}_{2} \mathrm{O}_{2}$ with endothelial cells rapidly depletes ATP and causes extracellular appearance of xanthine and hypoxanthine. In vitro exposure of endothelial cells to $\mathrm{H}_{2} \mathrm{O}_{2}$ reduced intracellular ATP concentration by $72 \%$ (19). Neutrophil cells have the ability to initiate margination through the endothelium out of the circulating pool into the tissue and may stimulate microglia to produce cytokines as IL-1 and tumor necrosis factor- $\alpha$ (TNF- $\alpha$ ). Expression of TNF- $\alpha$, IL-1, and IL-6 was observed more frequently in brain lesions of neonatal brains with periventricular leukomalacia than in those without periventricular leukomalacia (21). A recent study in cultured bovine cerebral microvascular cells during hypoxia/reoxygenation demonstrated the influence of TNF- $\alpha$ and IL-1 on the adhesion of neutrophils and monocytes to the endothelium (22). Further, oligodendrocytes in culture exposed to $\mathrm{H}_{2} \mathrm{O}_{2}$ may facilitate apoptotic cell death $(23,24)$, indicating that $\mathrm{H}_{2} \mathrm{O}_{2}$ appears to participate in the cascade to oligodendroglial cell death. Thus, the appearance of reactive oxygen species including $\mathrm{H}_{2} \mathrm{O}_{2}$ in circulating cells in the brain may have importance for progressive intracerebral oxidative mechanisms in connection with hypoxia and reoxygenation. The release of reactive oxygen species from circulating leukocytes may go on in the brain and induce sequestration of the perivascular microenvironment. Increasing experimental evidence indicates that PMN adhesion should be further investigated.

Normally produced $\mathrm{H}_{2} \mathrm{O}_{2}$ is necessary for bactericidal mechanisms in the neutrophil cell. $\mathrm{H}_{2} \mathrm{O}_{2}$ can be produced either spontaneously or by Superoxide dismutase (SOD)-catalyzed dismutation of $\mathrm{O}_{2}^{-}$. Our results suggest that the production of cerebral $\mathrm{H}_{2} \mathrm{O}_{2}$ is $\mathrm{O}_{2}$-dependent. This was also supported by a study in brains of rats exposed to room air where $\mathrm{H}_{2} \mathrm{O}_{2}$ was calculated to be $7.7 \mathrm{pM}$ and a rise of approximately $60 \%$ was reported when $\mathrm{O}_{2}$ tension was increased to $100 \%$ (25). Armstead et al. (26) have demonstrated a significant production of $\mathrm{O}_{2}{ }^{-}$anion $\left(8.7 \pm 1.5 \mathrm{pmol} / \mathrm{mm}^{-2} / 20 \mathrm{~min}\right)$ in connection with global cerebral ischemia-reperfusion in the newborn pig, and, recently, an increased free radical production by fetal brain in postasphyxial lambs was demonstrated (27) despite oxygen tensions of only $3-3.5 \mathrm{kPa}$. As indicated in human studies (28), accumulation of $\mathrm{H}_{2} \mathrm{O}_{2}$ during hypoxia and hyperoxia may reflect a high production of $\mathrm{O}_{2}{ }^{-}$. The effect of $100 \% \mathrm{O}_{2}$ on free radical formation was recently studied employing the electron spin resonance technique (4). The results of the latter study indicated that reoxygenation with $100 \% \mathrm{O}_{2}$ was associated with significantly more free radical generation than reoxygenation with $21 \% \mathrm{O}_{2}$. However, two studies have been performed in 
Table 5. $\mathrm{H}_{2} \mathrm{O}_{2}$ concentrations in PMN from arterial and cerebral venous (superior sagittal sinus) blood during baseline, hypoxia $\left(8 \% \mathrm{O}_{2}\right)$, and reoxygenation with 100 and $21 \% \mathrm{O}_{2}$

\begin{tabular}{|c|c|c|c|c|c|c|c|}
\hline Rho 123 & & & Hypoxia & & Reoxygenation (min) & & \\
\hline \multirow[b]{3}{*}{ Artery } & Group & Baseline & 5 & 60 & 5 & 60 & 120 \\
\hline & $100 \% \mathrm{O}_{2}$ & 100 & $102.9 \pm 9.7$ & $114.7 \pm 4.7 *$ & $106.7 \pm 11.6$ & $104.0 \pm 7.4$ & $101.0 \pm 17.5$ \\
\hline & $21 \% \mathrm{O}_{2}$ & 100 & $97.1 \pm 9.0$ & $132.2 \pm 14.5^{*}$ & $91.2 \pm 10.8$ & $93.4 \pm 8.2$ & $83.6 \pm 8.1$ \\
\hline \multirow[t]{3}{*}{ Sagittal sinus } & $100 \% \mathrm{O}_{2}$ & 100 & $107.4 \pm 8.4$ & $121.1 \pm 14.1 \Phi$ & $15.8 \pm 11.9 \S$ & $125.5 \pm 18.4 \S$ & $113.5 \pm 14.3 \S$ \\
\hline & $21 \% \mathrm{O}_{2}$ & 100 & $90.9 \pm 8.1$ & $113.7 \pm 8.69$ & $108.9 \pm 8.8$ & $86.2 \pm 6.3$ & $84.1 \pm 8.4$ \\
\hline & Control & 100 & $116.5 \pm 8.1$ & $100.1 \pm 11.1$ & $106.6 \pm 13.5$ & $93.8 \pm 18.7$ & $99.6 \pm 11.5$ \\
\hline
\end{tabular}

Results are changes expressed in percent from baseline (mean \pm SEM); groups: $100 \% \mathrm{O}_{2}(n=12), 21 \% \mathrm{O}_{2}(n=13)$, control $(n=5)$. Rho $123, \Delta$ ln Rho 123 fluorescence intensity - changes compared with baseline expressed in \%. * Indicates $\mathrm{p}<0.05 v s$ baseline (both groups combined), $\S$ indicates $\mathrm{p}<0.05 v s$ $21 \% \mathrm{O}_{2}$ group; $\uparrow$ indicates $\mathrm{p}=0.06$ ( $v s$ baseline, both groups combined).

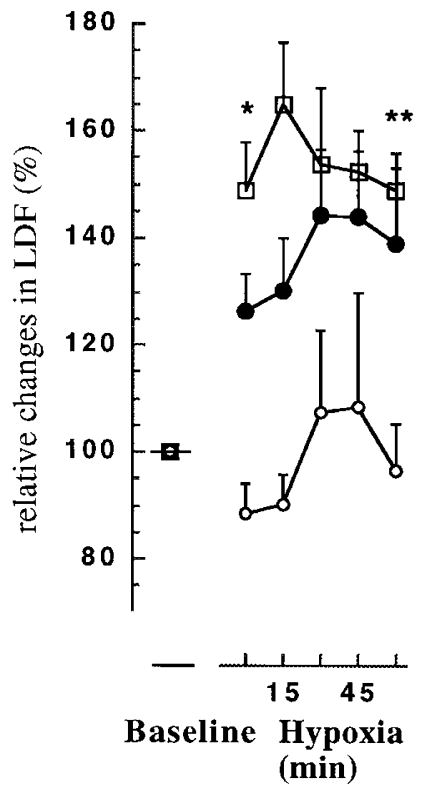

Figure 4. Relative changes in LDF compared with baseline during hypoxia and reoxygenation with 21 or $100 \% \mathrm{O}_{2}$ expressed in percentages (mean \pm SEM). ${ }^{*} p<0.05 v s$ control group; ${ }^{* *} p<0.05$ vs baseline.

which hyperoxia after brain ischemia was not found to increase the concentration of reactive oxygen metabolites $(5,7)$.

Accumulation of leukocytes may contribute to an increase in cerebral $\mathrm{H}_{2} \mathrm{O}_{2}$ concentration during reoxygenation with $100 \%$ $\mathrm{O}_{2} \cdot \mathrm{H}_{2} \mathrm{O}_{2}$ efflux (superior sagittal sinus) values were found to be significantly higher than the influx values (femoral artery) in the $100 \% \mathrm{O}_{2}$ but not in the room air group. The antioxidant defense capacity may be overwhelmed by reoxygenation with $100 \% \mathrm{O}_{2}$ due to an overload of reactive oxygen species. This could finally result in a higher cerebral $\mathrm{H}_{2} \mathrm{O}_{2}$ concentration, as demonstrated in this study. However, it is still unclear how effectively the newborn immature brain can mobilize a protective antioxidative response to the hyperoxic challenge.

It can be questioned whether the $\mathrm{FiO}_{2}$ was the only variable of interest associated with the changes of $\mathrm{H}_{2} \mathrm{O}_{2}$ concentrations. The influence of plasma glucose concentration on the brain in hypoxia-reoxygenation is still a matter of debate. As expected, in the present study, a slight increase of plasma glucose concentration during the hypoxic stress in both study groups was seen. Compared with the findings of Andersen et al. (4), it seems to us to be the most plausible explanation that oxygen is the most likely source of the $\mathrm{H}_{2} \mathrm{O}_{2}$ accumulation.
Another response to hypoxia and reoxygenation was an increase in PMN in the systemic circulation. Hallenbeck et al. (29) have shown in a canine model that cerebral hypoperfusion was associated with PMN accumulation in the injured brain hemisphere during the early postischemic period. Caceres et al. (30) showed in asphyxiated piglets that leukocyte accumulation occurred in cerebral arteries $4-6 \mathrm{~h}$ after the insult. Neutrophil accumulation in cerebral blood vessels may plug the microcirculation and cause damage from within the blood vessels during the first $24 \mathrm{~h}$ after asphyxia (31). This fits in with the observation that allopurinol-induced neutrophil depletion may be beneficial to the neonatal brain in rats exposed to hypoxia-ischemia (31). Neutrophils have a diameter of approximately $10 \mu \mathrm{m}$ and have to be deformed before passing through the capillaries. Activated neutrophils will cause obstruction due to the loss of their viscoelastic properties. Moreover, the activated endothelium may express adhesion molecules, which attract circulating neutrophils and cause them to adhere (32).

We found that hypoxemia caused an initial increase in cortical microvascular perfusion of approximately $150 \%$ of baseline values, after which the flow returned to normal values at approximately $60 \mathrm{~min}$ of reoxygenation. Unexpectedly, there was no further increase in perfusion after the start of reoxygenation in either study group. As demonstrated in previous studies, when the microsphere technique (33) or the LDF technique (34) was used to assess regional cerebral blood flow in the cortex, the circulation was restored as efficiently with 21 as with $100 \% \mathrm{O}_{2}$. However, the latter findings do not necessarily prove that there are no differences in deeper and more sensitive brain regions.

Hypoxia induced a decrease in forebrain oxygen uptake $\left(\mathrm{CMRO}_{2}\right)$, which became restored during reoxygenation. After the start of reoxygenation, room air tended to induce a higher $\mathrm{CMRO}_{2}$ than $100 \% \mathrm{O}_{2}$, which became significant after $60 \mathrm{~min}$. It seemed that reoxygenation with $100 \% \mathrm{O}_{2}$ reduced the $\mathrm{O}_{2}$ extraction and utilization in the predominantly cortical brain areas assessed in the present study. This depression in the $\mathrm{O}_{2}$ metabolism when oxygen is available in excess may reflect a protective mechanism possessed by the whole brain or a lower metabolic rate of oxygen in tissues drained by the superior sagittal sinus.

The fact that formation of $\mathrm{H}_{2} \mathrm{O}_{2}$ in cerebral venous PMN during reoxygenation with $21 \% \mathrm{O}_{2}$ was lower, in contrast with the concentration found during reoxygenation with $100 \% \mathrm{O}_{2}$, and that cortical vascular perfusion was restored in both groups 
indicates that care must be taken when higher $\mathrm{O}_{2}$ concentrations are used. Reducing the $\mathrm{O}_{2}$ to a more moderate level may be of therapeutic importance, a proposition that should be further examined.

In conclusion, $\mathrm{H}_{2} \mathrm{O}_{2}$ concentration in arterial PMN of newborn piglets increased during hypoxia and tended to increase in PMN from cerebral venous blood. During reoxygenation, neutrophil cells accumulated in the systemic arterial circulation. At the same time, $\mathrm{H}_{2} \mathrm{O}_{2}$ concentration in $\mathrm{PMN}$ in the cerebral circulation was low with room air but remained high with pure oxygen ventilation. Further, cortical microvascular perfusion increased during transient hypoxia and was almost normalized after reoxygenation in both study groups. We speculate that reoxygenation with increased oxygen concentrations may have side effects. This indicates that oxygen should be reintroduced with caution during neonatal resuscitation.

Acknowledgment. The authors thank Mette K. Olafsen for her advice on the use of the FACScan flow cytometer.

\section{REFERENCES}

1. Gerschman R, Gilbert DL, Nyl SW 1954 Oxygen poisoning and x-ray irradiation: a mechanism in common. Science 119:624-626

2. Palmer C 1995 Hypoxic-ischemic encephalopathy. Therapeutic approaches agains microvascular injury, and role of neutrophils, PAF, and free radicals. Clin Perinatol 22:481-517

3. Fellman V, Raivio KO 1997 Reperfusion injury as the mechanism of brain damage after perinatal asphyxia. Pediatr Res 41:599-606

4. Andersen CB, Hoffman DJ, Du C, McGowan JE, Ohnishi ST, DelivoriaPapadopoulos M 1997 Effect of reoxygenation with $21 \%$ or $100 \%$ oxygen on free radical formation following hypoxia in the cerebral cortex of newborn piglets. Pediatr Res 41:30A(abstr)

5. Cino M, Del Maestro RF 1989 Generation of hydrogen peroxide by brain mitochondria: the effect of reoxygenation following postdecapitative ischemia. Arch Biochem Biophys 269:623-638

6. Mickel HS, Vaishnav YN, Kempski O, von Lubitz D, Weiss JF, Feuerstein G 1987 Breathing $100 \%$ oxygen after global brain ischemia in Mongolian gerbils results in increased lipid peroxidation and increased mortality. Stroke 18:426-430

7. Agardh CD, Zhang H, Smith ML, Siesjo BK 1991 Free radical production and ischemic brain damage: influence of postischemic oxygen tension. Int J Dev Neurosci 9:127-138

8. Bass DA, Parce JW, Dechatelet LR, Szejda P, Seeds MC, Thomas M 1983 Flow cytometric studies of oxidative product formation by neutrophils: a graded response to membrane stimulation. J Immunol 130:1910-1917

9. Emmendorffer A, Hecht M, Lohmann-Matthes ML, Roesler J 1990 A fast and easy method to determine the production of reactive oxygen intermediates by human and murine phagocytes using dihydrorhodamine 123. J Immunol Methods 131:269-275

10. Lehrer RI, Ganz T 1990 Antimicrobial polypeptides of human neutrophils. Blood $76: 2169-2181$

11. Henderson LM, Chappell JB 1993 Dihydrorhodamine 123: a fluorescent probe for superoxide generation? Eur J Biochem 217:973-980

12. van Pelt LJ, van Zwieten R, Weening RS, Roos D, Verhoeven AJ, Bolscher BG 1996 Limitations on the use of dihydrorhodamine 123 for flow cytometric analysis of the neutrophil respiratory burst. J Immunol Methods 191:187-196
13. Rothe G, Oser A, Valet G 1988 Dihydrorhodamine 123: a new flow cytometric indicator for respiratory burst activity in neutrophil granulocytes. Naturwissenschaften 75:354-355

14. Eyre JA, Essex TJ, Flecknell PA, Bartholomew PH, Sinclair JI 1988 A comparison of measurements of cerebral blood flow in the rabbit using laser Doppler spectroscopy and radionuclide labelled microspheres. Clin Phys Physiol Meas 9:65-74

15. Kirkeby OJ, Rise IR, Nordsletten L, Skjeldal S, Hall C, Risoe C 1995 Cerebral blood flow measured with intracerebral laser-Doppler flow probes and radioactive microspheres. J Appl Physiol 79:1479-1486

16. Johansson K, Jakobsson A, Lindahl K, Lindhagen J, Lundgren O, Nilsson GE 1991 Influence of fibre diameter and probe geometry on the measuring depth of laser Doppler flowmetry in the gastrointestinal application. Int $\mathrm{J}$ Microcirc Clin Exp 10:219-229

17. Smith JA, Weidemann MJ 1993 Further characterization of the neutrophil oxidative burst by flow cytometry. J Immunol Methods 162:261-268

18. Emmendorffer A, Nakamura M, Rothe G, Spiekermann K, Lohmann-Matthes ML, Roesler J 1994 Evaluation of flow cytometric methods for diagnosis of chronic granulomatous disease variants under routine laboratory conditions. Cytometry 18:147-155

19. Ward PA 1991 Mechanisms of endothelial cell killing by $\mathrm{H} 2 \mathrm{O} 2$ or products of activated neutrophils. Am J Med 91:89S-94S

20. Fantone JC, Ward PA 1982 Role of oxygen-derived free radicals and metabolites in leukocyte-dependent inflammatory reactions. Am J Pathol 107:395-418

21. Yoon BH, Romero R, Kim CJ, Koo JN, Choe G, Syn HC, Chi JG 1997 High expression of tumor necrosis factor-alpha and interleukin-6 in periventricular leukomalacia. Am J Obstet Gynecol 177:406-411

22. Li TJ, Rui YC, Xu JP 1999 Effects of hypoxia/reoxygenation and cytokines on adhesion of leukocytes to cerebral microvascular endothelial cells. Zhongguo Yao Li Xue Bao 20:137-140

23. Kameshwar-Rao AS, Gil S, Richter-Landsberg C, Givol D, Yavin E 1999 H2O2induced apoptotic death in serum-deprived cultures of oligodendroglia origin is linked to cell differentiation. J Neurosci Res 56:447-456

24. Richter-Landsberg C, Vollgraf U 1998 Mode of cell injury and death after hydrogen peroxide exposure in cultured oligodendroglia cells. Exp Cell Res 244:218-229

25. Yusa T, Beckman JS, Crapo JD, Freeman BA 1987 Hyperoxia increases H2O2 production by brain in vivo. J Appl Physiol 63:353-358

26. Armstead WM, Mirro R, Busija DW, Leffler CW 1988 Postischemic generation of superoxide anion by newborn pig brain. Am J Physiol 255:H401-H403

27. Bagenholm R, Nilsson UA, Gotborg CW, Kjellmer I 1998 Free radicals are formed in the brain of fetal sheep during reperfusion after cerebral ischemia. Pediatr Res 43:271-275

28. Shigeoka AO, Charette RP, Wyman ML, Hill HR 1981 Defective oxidative metabolic responses of neutrophils from stressed neonates. J Pediatr 98:392-398

29. Hallenbeck JM, Dutka AJ, Tanishima T, Kochanek PM, Kumaroo KK, Thompson CB, Obrenovitch TP, Contreras TJ 1986 Polymorphonuclear leukocyte accumulation in brain regions with low blood flow during the early postischemic period. Stroke 17:246-253

30. Caceres MJ, Schleien CL, Kuluz JW, Gelman B, Dietrich WD 1995 Early endothelial damage and leukocyte accumulation in piglet brains following cardiac arrest. Acta Neuropathol (Berl) 90:582-591

31. Hudome S, Palmer C, Roberts RL, Mauger D, Housman C, Towfighi J 1997 The role of neutrophils in the production of hypoxic-ischemic brain injury in the neonatal rat. Pediatr Res 41:607-616

32. Hudetz AG, Wood JD, Kampine JP 1999 Nitric oxide synthase inhibitor augments post-ischemic leukocyte adhesion in the cerebral microcirculation in vivo. Neurol Res 21:378-384

33. Rootwelt T, Loberg EM, Moen A, Oyasaeter S, Saugstad OD 1992 Hypoxemia and reoxygenation with $21 \%$ or $100 \%$ oxygen in newborn pigs: changes in blood pressure, base deficit, and hypoxanthine and brain morphology. Pediatr Res 32:107-113

34. Kutzsche S, Kirkeby OJ, Rise IR, Saugstad OD 1999 Effects of hypoxia and reoxygenation with $21 \%$ and $100 \%$ oxygen on cerebral nitric oxide concentration and microcirculation in newborn piglets. Biol Neonate 76:153-167 